\title{
Kebutuhan Transfusi Darah Pasca-Splenektomi pada Thalassemia Mayor
}

\author{
Murti Andriastuti, Teny Tjitra Sari, Pustika Amalia Wahidiyat, Siti Ayu Putriasih \\ Departemen Ilmu Kesehatan Anak Fakultas Kedokteran Universitas Indonesia RS Cipto Mangunkusumo, \\ Jakarta
}

Latar belakang. Transfusi darah merupakan pengobatan satu-satunya bagi pasien thalassemia guna mempertahankan kadar hemoglobin darah. Salah satu cara mengurangi kebutuhan darah adalah dengan melakukan splenektomi.

Tujuan. Membandingkan kebutuhan transfusi pra-splenektomi dan pasca-splenektomi.

Metode. Studi deskriptif terhadap pasien thalassemia $\beta$ dan thalassemia- $\beta / \mathrm{HbE}$ yang dilakukan splenektomi di Pusat Thalassemia Departemen Ilmu Kesehatan Anak, RS Dr Cipto Mangunkusumo tahun 2006-2009. Data yang dikumpulkan adalah kadar $\mathrm{Hb}$ pra-transfusi, jumlah kebutuhan darah, dan frekuensi transfusi darah dalam rentang setahun sebelum dan setahun setelah splenektomi, serta indikasi splenektomi. Didapat 98 pasien pasca- splenektomi tetapi 3 pasien dikeluarkan karena data tidak lengkap.

Hasil. Subjek penelitian 98 pasien pasca- splenektomi terdiri 47 lelaki dan 51 perempuan. Rerata jarak waktu pertama kali transfusi darah sampai dilakukan splenektomi adalah 10 (SB 5,0) tahun, kisaran 8 bulan-23 tahun. Rerata ukuran limpa saat splenektomi adalah Schufner VI, kisaran Schufner II-VIII. Terjadi peningkatan rerata Hb pra-transfusi pra-splenektomi sebesar 6,2 (SB 0,9) $\mathrm{g} / \mathrm{dL}$, rentang 4,4-8,6 g/dL, pasca-splenektomi meningkat menjadi 7,9 (SB 0,8) g/dL, kisaran 5,6-10 g/dL. Rerata jumlah kebutuhan transfusi darah pra-splenektomi sebesar 357,2 (SB $101,2) \mathrm{mL} / \mathrm{kgBB} /$ tahun, pasca-splenektomi menurun menjadi 131,1 (SB 57,5) $\mathrm{mL} / \mathrm{kgBB} / \mathrm{tahun}$. Rerata frekuensi transfusi darah pra-splenektomi 15 (SB 3,7) kali per tahun, kisaran 6-24 kali per tahun, pasca-splenektomi menjadi 8 (SB 3) kali per tahun, kisaran 0-14 kali per tahun. Indikasi splenektomi adalah hipersplenisme dini (53 subjek) dan hipersplenisme lanjut (45 subjek). Rerata $\mathrm{Hb}$ pra-transfusi pasca-splenektomi subjek hipersplenisme dini $(8,3 \mathrm{~g} / \mathrm{dL})$ lebih tinggi dibandingkan subjek hipersplenisme lanjut $(7,6 \mathrm{~g} / \mathrm{dL})(\mathrm{p}=0,000)$. Terdapat perbedaan bermakna jumlah kebutuhan darah pasca-splenektomi thalassemia- $\beta / \mathrm{HbE}(108,6 \mathrm{~mL} / \mathrm{kgBB} / \mathrm{tahun})$ dan thalassemia- $\beta(144,1 \mathrm{~mL} /$ $\mathrm{kgBB} /$ tahun) ( $\mathrm{p}=0,001)$. Frekuensi transfusi darah thalassemia- $\beta / \mathrm{HbE}$ pasca-splenektomi $(7 \mathrm{x} /$ tahun) lebih rendah daripada thalassemia- $\beta(9 \mathrm{x} /$ tahun $)(\mathrm{p}=0,011)$. Tidak didapatkan adanya perbedaan yang bermakna antara rerata $\mathrm{Hb}$ pra-transfusi pasca-splenektomi antara thalassemia- $\beta$ dengan thalassemia- $\beta / \mathrm{HbE}(\mathrm{p}=0,132)$.

Kesimpulan. Terdapat perbedaan kebutuhan transfusi antara pra-splenektomi dan pasca splenektomi berdasarkan jenis hipersplenisme dan genotip pasien. Kebutuhan transfusi pasca splenektomi lebih sedikit apabila splenektomi dianjurkan pada keadaan hipersplenisme dini dan kasus thalassemia $\beta / \mathrm{HbE}$. Sari Pediatri 2011;13(4):244-9.

Kata kunci: thalassemia mayor, transfusi darah, pasca-splenektomi

\footnotetext{
Alamat korespondensi:

Dr. Murti Andriastuti, SpA. Divisi Hematologi Onkologi Departemen

Ilmu Kesehatan Anak FKUI- RSCM Jl. Salemba no. 6, Jakarta 10430.

Telepon: 021-3907744, 31901170 Fax.021-3913982.
} 
卫T halassemia merupakan kelainan genetik yang paling banyak ditemukan di Indonesia. Thalassemia disebabkan oleh berkurang atau tidak disintesis rantai globin- $\alpha$ atau $-\beta$ (komponen utama molekul hemoglobin dewasa $-\alpha_{2} \beta_{2}$ ) yang diturunkan secara autosomal resesif. Angka pembawa sifat thalassemia- $\alpha$, thalassemia- $\beta$, dan HbE berturut-turut 2,6\%-11\%, 3-10\%, dan 1,5\%$36 \%{ }^{1,2}$ Angka kejadian thalassemia terus meningkat setiap tahunnya. Di Pusat Thalassemia, Departemen Ilmu Kesehatan Anak, RS Dr Cipto Mangunkusumo (RSCM), jumlah pasien baru mencapai 80-100 pasien per tahun. ${ }^{3}$ Jumlah pasien terdaftar di Pusat Thalassaemia sampai dengan bulan Juli 2010, 1.544 pasien terdiri atas thalassemia- $\beta 50,4 \%$, thalassemia- $\beta$ / $\mathrm{HbE} 47,1 \%$, thalassemia- $\alpha 2 \%$, dan sisanya lainlain. ${ }^{3}$

Sampai saat ini thalassemia belum dapat disembuhkan. Pengobatan yang dilakukan hanya untuk memperpanjang usia harapan hidup dan meningkatkan kualitas hidup pasien. Biaya pengobatan suportif (transfusi darah dan kelasi besi) untuk seumur hidup sangat besar sekitar Rp 200-300 juta/tahun/pasien. ${ }^{4}$ Biaya tersebut di luar biaya jika terjadi komplikasi yang timbul pada akhir dekade pertama atau awal dekade kedua kehidupan.

Transfusi darah masih merupakan pengobatan satu-satunya bagi pasien thalassemia guna mempertahankan kadar hemoglobin darah. Pemberian transfusi darah pada pasien thalassemia sebaiknya tidak hanya berdasarkan keluhan pucat tetapi pada adanya gejala ketidakmampuan tubuh mengompensasi kadar hemoglobin yang rendah. Gejala tersebut antara lain takikardia, lemas, gangguan pertumbuhan atau gejala proses eritropoiesis yang tidak adekuat, seperti perubahan bentuk tulang atau splenomegali masif. ${ }^{5}$

Pemberian transfusi darah dilakukan pada kadar $\mathrm{Hb}$ pra-transfusi $\leq 8 \mathrm{~g} / \mathrm{dL} .{ }^{6}$ Frekuensi transfusi darah umumnya $1 x /$ bulan. Pada pasien dengan hipersplenisme kebutuhan darah meningkat sehingga mereka membutuhkan transfusi darah 2-3x/bulan. Pemberian transfusi darah yang adekuat disertai kelasi besi secara teratur dapat mencapai proses tumbuh kembang yang optimal. Namun di sisi lain, pemberian transfusi darah memiliki risiko antara lain penularan penyakit infeksi (hepatitis B, hepatitis C, HIV) maupun penumpukan besi di seluruh organ tubuh terutama di otot jantung dan hati.
Salah satu upaya mengurangi kebutuhan transfusi darah pada pasien thalassemia adalah dengan splenektomi. Tindakan splenektomi harus dipertimbangkan secara matang karena adanya risiko infeksi pasca tindakan. ${ }^{6}$ Diharapkan pascasplenektomi, kebutuhan transfusi darah akan berkurang sehingga dapat mengurangi efek samping akibat transfusi darah.

Tujuan penelitian untuk mengetahui perbedaan kebutuhan transfusi sebelum dan setelah splenektomi.

\section{Metode}

Tidak dilakukan studi deskriptif terhadap pasien thalassemia yang telah dilakukan splenektomi di Pusat Thalassemia Departemen Ilmu Kesehatan Anak, RS Dr Cipto Mangunkusumo (RSCM) pada tahun 2006-2009. Didapatkan 101 subjek, namun hanya 98 subjek yang mempunyai data lengkap. Data yang dikumpulkan adalah kadar Hb pra-transfusi, jumlah kebutuhan darah, dan frekuensi transfusi darah dihitung selama rentang setahun sebelum dan setahun setelah splenektomi. Data lain yang dikumpulkan adalah indikasi splenektomi, jenis hipersplenisme dan genotip pasien (thalassemia- $\beta$ mayor dan thalassemia- $\beta / \mathrm{HbE}$ ). Indikasi dilakukan splenektomi antara lain kebutuhan transfusi darah yang meningkat, yakni melebihi $250 \mathrm{~mL} / \mathrm{kgBB} /$ tahun (hipersplenisme dini), adanya pansitopenia pada pemeriksaan darah perifer (hipersplenisme lanjut), atau alasan mekanik karena limpa yang sangat besar, umumnya melebihi ukuran Schufner IV sehingga membatasi gerak pasien, menimbulkan tekanan intra-abdominal yang mengganggu pernapasan dan berisiko mengalami ruptur. ${ }^{6,78}$

\section{Hasil}

Subjek penelitian 98 anak, terdiri atas 47 lelaki dan 51 perempuan. Sebanyak $62(63 \%)$ subjek adalah thalassemia- $\beta$ mayor, sisanya 36 (37\%) subjek adalah thalassemia- $\beta / \mathrm{HbE}$. Rerata usia saat diagnosis 2 (SB 2,7) tahun dengan kisaran 1 bulan-13 tahun. Rerata usia splenektomi 13 (SB 5,1) tahun dengan kisaran 3-27 tahun. Rerata jarak waktu pertama kali transfusi darah sampai dilakukan splenektomi 10 (SB 5,0) tahun dengan kisaran 8 bulan-23 tahun. Sebagian besar 
pasien $(70,4 \%)$ mempunyai limpa yang besar dengan terbanyak ukuran limpa saat splenektomi adalah Schufner VI dengan kisaran Schufner II-VIII.

Sebagian besar subjek $(96,9 \%)$ memiliki kadar $\mathrm{Hb}$ pra-transfusi pasca-splenektomi lebih tinggi dibandingkan pra-splenektomi. Rerata $\mathrm{Hb}$ pratransfusi sebelum splenektomi 6,2 (SB 0,9) g/ $\mathrm{dL}$ dengan kisaran antara 4,4-8,6 g/dL, pascasplenektomi meningkat menjadi 7,9 (SB 0,8) g/dL dengan kisaran antara 5,6-10 g/dL. Rerata jumlah kebutuhan darah pra-splenektomi 357,2 (SB 101,2) $\mathrm{mL} / \mathrm{kgBB} /$ tahun, pasca-splenektomi menurun menjadi 131,1 (SB 57,5) mL/kgBB/tahun. Sama halnya dengan jumlah kebutuhan darah, frekuensi transfusi darah pada semua subjek pasca-splenektomi mengalami penurunan. Rerata frekuensi transfusi darah pra-splenektomi 15 (SB 3,7) kali per tahun dengan kisaran antara 6-24 kali per tahun, pascasplenektomi menurun menjadi 8 (SB 3) kali per tahun dengan kisaran antara 0-14 kali per tahun. Frekuensi transfusi darah pada 5 subjek menjadi jarang (3-4x/ tahun) dari sebelumnya rutin $1 \mathrm{x} /$ bulan. Bahkan frekuensi transfusi darah pada 4 subjek menurun drastis dari setiap bulan menjadi setiap 6-12 bulan, ke-4 subjek tersebut didiagnosis sebagai thalassemia- $\beta$ homozigot.

Tabel 1. Profil rerata Hb pra-transfusi, jumlah kebutuhan darah, dan frekuensi transfusi darah pasien splenektomi berdasarkan hipersplenisme dini dan hipersplenisme lanjut

\begin{tabular}{|c|c|c|c|c|c|}
\hline \multirow[b]{2}{*}{ Parameter } & \multicolumn{2}{|c|}{ Hipersplenisme dini $(n=53)$} & \multicolumn{2}{|c|}{ Hipersplenisme lanjut $(\mathrm{n}=45)$} & \multirow[b]{2}{*}{ Nilai p¥ } \\
\hline & $\begin{array}{c}\text { Pra- } \\
\text { splenektomi }\end{array}$ & $\begin{array}{c}\text { Pasca- } \\
\text { splenektomi }\end{array}$ & $\begin{array}{c}\text { Pra- } \\
\text { splenektomi }\end{array}$ & $\begin{array}{c}\text { Pasca- } \\
\text { splenektomi }\end{array}$ & \\
\hline $\begin{array}{l}\text { Hb pra-transfusi } \\
(\mathrm{g} / \mathrm{dL})\end{array}$ & $\begin{array}{c}6,6 \\
(\mathrm{SB} 0,9)\end{array}$ & $\begin{array}{c}8,3 \\
(\mathrm{SB} 0,8)\end{array}$ & $\begin{array}{c}5,8 \\
(\mathrm{SB} 0,7)\end{array}$ & $\begin{array}{c}7,6 \\
(\mathrm{SB} 0,7)\end{array}$ & $0,000^{*}$ \\
\hline $\begin{array}{l}\text { Kebutuhan darah } \\
\text { (mL/kgBB/tahun) }\end{array}$ & $\begin{array}{c}333,8 \\
(\mathrm{SB} 96,1)\end{array}$ & $\begin{array}{c}121,8 \\
(\mathrm{SB} 60,6)\end{array}$ & $\begin{array}{l}384,7 \\
(101,2)\end{array}$ & $\begin{array}{c}142,0 \\
(\mathrm{SB} 52,3)\end{array}$ & $0,084^{*}$ \\
\hline $\begin{array}{l}\text { Frekuensi transfusi darah } \\
\text { (kali/tahun) }\end{array}$ & $\begin{array}{c}14,3 \\
(\mathrm{SB} 3,7)\end{array}$ & $\begin{array}{c}7,9 \\
(\mathrm{SB} 3,2)\end{array}$ & $\begin{array}{c}15,8 \\
(\mathrm{SB} 3,6)\end{array}$ & $\begin{array}{c}8,5 \\
(\mathrm{SB} 2,7)\end{array}$ & $0,207^{* *}$ \\
\hline $\begin{array}{lll}\text { Ket. } & ¥ & \text { Membandingkan keadaar } \\
& * & \text { Uji-t tidak berpasangan } \\
& * * & \text { Uji Mann-Whitney }\end{array}$ & splenektomi & & & & \\
\hline
\end{tabular}

Tabel 2. Profil rerata $\mathrm{Hb}$ pra-transfusi, jumlah kebutuhan darah, dan frekuensi transfusi darah pasien splenektomi berdasarkan thalassemia- $\beta$ dan thalassemia- $\beta / \mathrm{HbE}$

\begin{tabular}{|c|c|c|c|c|c|c|}
\hline \multirow{2}{*}{\multicolumn{2}{|c|}{ Parameter }} & \multicolumn{2}{|c|}{ Thalassemia- $\beta(n=62)$} & \multicolumn{2}{|c|}{ Thalassemia- $\beta / \mathrm{HbE}(\mathrm{n}=36)$} & \multirow[b]{2}{*}{ Nilai p¥ } \\
\hline & & $\begin{array}{c}\text { Pra- } \\
\text { splenektomi }\end{array}$ & $\begin{array}{c}\text { Pasca- } \\
\text { splenektomi }\end{array}$ & $\begin{array}{c}\text { Pra- } \\
\text { splenektomi }\end{array}$ & $\begin{array}{c}\text { Pasca- } \\
\text { splenektomi }\end{array}$ & \\
\hline $\begin{array}{l}\mathrm{Hb} \\
(\mathrm{g} / \mathrm{d})\end{array}$ & $\begin{array}{l}\text { pra-transfusi } \\
\text { L) }\end{array}$ & $\begin{array}{c}6,2 \\
(\mathrm{SB} 0,9)\end{array}$ & $\begin{array}{c}7,8 \\
(\mathrm{SB} 0,9)\end{array}$ & $\begin{array}{c}6,3 \\
(\mathrm{SB} 1,0)\end{array}$ & $\begin{array}{c}8,1 \\
(\mathrm{SB} 0,7)\end{array}$ & $0,132^{*}$ \\
\hline $\begin{array}{l}\text { Kebu } \\
(\mathrm{mL}\end{array}$ & $\begin{array}{l}\text { utuhan darah } \\
\text { /kgBB/tahun) }\end{array}$ & $\begin{array}{c}370,9 \\
(\text { SB } 103,6)\end{array}$ & $\begin{array}{c}144,1 \\
(\mathrm{SB} 60,8)\end{array}$ & $\begin{array}{c}333,6 \\
(\mathrm{SB} 93,6)\end{array}$ & $\begin{array}{c}108,6 \\
(\mathrm{SB} 43,6)\end{array}$ & $0,001^{*}$ \\
\hline $\begin{array}{l}\text { Frek } \\
\text { (kali }\end{array}$ & $\begin{array}{l}\text { uensi transfusi darah } \\
\text { /tahun) }\end{array}$ & $\begin{array}{c}15,5 \\
(\mathrm{SB} 3,7)\end{array}$ & $\begin{array}{c}8,6 \\
(\mathrm{SB} 3,2)\end{array}$ & $\begin{array}{c}14,1 \\
(\mathrm{SB} 3,6)\end{array}$ & $\begin{array}{c}7,3 \\
(\mathrm{SB} 2,6)\end{array}$ & $0,011^{*}$ \\
\hline Ket. & $\begin{array}{ll} & \text { Membandingkan } \\
* & \text { Uji-t tidak berpasa } \\
* * & \text { Uji Mann-Whitne }\end{array}$ & a splenektomi & & & & \\
\hline
\end{tabular}


Limapuluh tiga dari 98 subjek (54\%) dilakukan splenektomi karena meningkatnya kebutuhan transfusi (hipersplenisme dini), sisanya 45 (46\%) subjek karena sudah terjadi pansitopenia (hipersplenisme lanjut). Rerata $\mathrm{Hb}$ pra-transfusi subjek pasca-splenektomi, baik karena hipersplenisme dini maupun hipersplenisme lanjut, lebih tinggi dibandingkan pra-splenektomi. Demikian halnya dengan rerata jumlah kebutuhan darah dan rerata frekuensi transfusi darah yang menurun pasca-splenektomi dibandingkan prasplenektomi (Tabel 1).

Hasil uji-t menunjukkan rerata $\mathrm{Hb}$ pra-transfusi pasca-splenektomi antara subjek hipersplenisme dini berbeda secara bermakna dengan subjek hipersplenisme lanjut $(\mathrm{p}=0,000)$. Rerata $\mathrm{Hb}$ pra-transfusi pasca-splenektomi subjek hipersplenisme dini $(8,3 \mathrm{~g} /$ $\mathrm{dL})$ lebih tinggi dibandingkan subjek hipersplenisme lanjut $(7,6 \mathrm{~g} / \mathrm{dL})$. Tidak ada perbedaan yang bermakna jumlah kebutuhan darah pasca-splenektomi antara kedua kelompok tersebut, dengan rerata kebutuhan darah pasca-splenektomi subjek hipersplenisme dini (121,8 $\mathrm{mL} / \mathrm{kgBB} /$ tahun) lebih rendah dibandingkan subjek hipersplenisme lanjut ( $142 \mathrm{~mL} / \mathrm{kgBB} /$ tahun) $(\mathrm{p}=0,084)$.

Untuk analisis statistik frekuensi transfusi darah dilakukan dengan uji Mann-Whitney karena data tidak terdistribusi normal. Hasilnya didapatkan frekuensi transfusi darah pasca-splenektomi antara subjek hipersplenisme dini tidak berbeda secara bermakna dengan subjek hipersplenisme lanjut $(\mathrm{p}=0,207)$.

Didapatkan 62 subjek $(63,3 \%)$ adalah thalassemia- $\beta$ dan sisanya (36,7\%) adalah thalassemia- $\beta / \mathrm{HbE}$. Secara umum subjek thalassemia- $\beta$ dan thalassemia- $\beta / \mathrm{HbE}$ memperlihatkan adanya peningkatan rerata $\mathrm{Hb}$ pratransfusi serta penurunan jumlah kebutuhan darah dan frekuensi transfusi darah pasca-splenektomi (Tabel 2).

Tabel 2 menunjukkan hanya jumlah kebutuhan darah dan frekuensi transfusi darah pasca-splenektomi yang berbeda secara bermakna antara subjek thalassemia- $\beta$ dengan thalassemia- $\beta / \mathrm{HbE}$. Jumlah kebutuhan darah subjek thalassemia- $\beta / \mathrm{HbE}$ $(108,6 \mathrm{~mL} / \mathrm{kgBB} /$ tahun) lebih rendah dari subjek thalassemia- $\beta$ (144,1 mL/kgBB/tahun) $(\mathrm{p}=0,001)$. Frekuensi transfusi darah subjek thalassemia- $\beta$ / $\mathrm{HbE}$ (7x/tahun) juga lebih rendah dari subjek thalassemia- $\beta$ (9x/tahun) ( $\mathrm{p}=0,011)$. Sementara itu tidak didapatkan adanya perbedaan yang bermakna antara rerata $\mathrm{Hb}$ pra-transfusi pasca-splenektomi antara subjek thalassemia- $\beta$ dengan thalassemia- $\beta$ / $\operatorname{HbE}(\mathrm{p}=0,132)$.

\section{Pembahasan}

Prevalensi splenektomi di Pusat Thalassaemia RSCM 13,7\%, berbeda jauh dengan penelitian Hawsawi $\mathrm{dkk}^{8}$ yang mendapatkan prevalensi splenektomi $32 \%$. Indikasi splenektomi lebih banyak (54\%) karena kebutuhan transfusi yang meningkat (hipersplenisme dini) dan sisanya (46\%) karena sudah terjadi trombositopenia dan atau leukopenia (hipersplenisme lanjut). Menurut kepustakaan, indikasi splenektomi yang lebih sensitif adalah meningkatnya kebutuhan transfusi, ${ }^{5}$ Hawsawi dkk $(2001)^{8}$ mendapatkan indikasi splenektomi yang terbanyak adalah kebutuhan transfusi yang meningkat (17/18). Perbedaan persentase ini dapat disebabkan sebagian besar subjek menunda atau tertunda karena tempat perawatan pra- dan pasca-operasi yang terbatas sampai akhirnya terjadi hipersplenisme lanjut.

Penelitian Wolff $\mathrm{dkk}^{9}$ menunjukkan splenektomi mampu meningkatkan rerata kadar $\mathrm{Hb}$ pra-transfusi. Walau demikian, splenektomi yang dilakukan dengan keadaan sudah hipersplenisme lanjut memberikan luaran lebih buruk. Peningkatan rerata $\mathrm{Hb}$ pratransfusi pasca splenektomi pasien hipersplenisme lanjut $(7,6(\mathrm{SB} 0,6) \mathrm{g} / \mathrm{dL})$ lebih rendah dibanding hipersplenisme dini $(8,3(\mathrm{SB} 0,8) \mathrm{g} / \mathrm{dl})(\mathrm{p}=0,000$; IK $95 \%$ 0,392-1,010). Sedangkan untuk frekuensi transfusi darah dan jumlah kebutuhan darah tidak ada perbedaan yang bermakna antara keduanya.

Rerata usia saat splenektomi 13 tahun dengan usia termuda 3 tahun. Pada pasien yang dilakukan splenektomi usia 3 tahun karena sudah terjadi trombositopenia dan leukopenia. Sampai saat ini subjek masih berobat secara teratur dan tidak pernah mengalami infeksi berat. Thalassemia International Federation menganjurkan usia untuk dilakukan splenektomi di atas 5 tahun. ${ }^{6} \mathrm{Hal}$ ini disebabkan fungsi organ lain belum sempurna dalam mempertahankan imunitas tubuh. Risiko terjadinya sepsis akan meningkat dua kali lipat jika splenektomi dilakukan pada usia kurang dari 4 tahun. ${ }^{10}$ Apabila terpaksa dilakukan sebelum umur 4 tahun dianjurkan untuk dilakukan splenektomi parsial dengan tujuan 
mengurangi tekanan mekanik akibat limpa yang membesar tetapi fungsi imunitasnya tetap ada. Namun ada 2 masalah pada splenektomi parsial ini, yaitu limpa dapat membesar kembali, besarnya volume limpa yang harus ditinggalkan di dalam rongga abdomen agar masih dapat berfungsi sebagai organ RES (reticulo endotel system) ${ }^{6,11}$

Hal lain yang harus diperhatikan adalah memastikan penghancuran sistem hematopoiesis terutama terjadi di limpa atau di organ RES lainnya seperti hati. Selain itu ada tidaknya limpa tambahan yang sering menyebabkan hasil operasi tidak sesuai dengan harapan. Idealnya untuk memastikan penghancuran sel darah terjadi di limpa atau organ RES lainnya seperti hati, sebelum operasi dilakukan pemeriksaan radiologis menggunakan radioisotop Cromium $\left(\mathrm{Cr}^{51}\right)$ guna melihat aktifitas organ RES terbesar dalam hal menghancurkan sistem hematopoiesis. ${ }^{6}$

Idealnya saat merencanakan tindakan splenektomi diberikan vaksinasi terhadap hepatitis B, pneumokokus, dan $H$. influenza dalam kurun waktu 2 minggu sebelum atau 2 minggu sesudah tindakan operasi dilakukan. ${ }^{6}$ Sayangnya hal ini belum dapat dilakukan karena biaya yang diperlukan cukup besar. Hal ini terlihat dari beberapa kasus asplenik yang reaksinya menjadi sangat berat bila mendapat infeksi, bahkan beberapa di antaranya meninggal dalam waktu singkat. Kemungkinan terjadi infeksi pasca-splenektomi menunjukkan sistem kekebalan limpa tetap utuh meskipun proses hemolitik terjadi terus menerus. ${ }^{12}$

Penelitian kami juga memperlihatkan jumlah kebutuhan darah dan frekuensi transfusi darah subjek thalassemia- $\beta / \mathrm{HbE}$ pasca splenektomi lebih rendah dari subjek thalassemia- $\beta$. Sedangkan untuk kadar $\mathrm{Hb}$ pra-transfusi tidak ada perbedaan yang bermakna antara keduanya. Perbedaan keduanya mungkin disebabkan adanya kelainan genetik sehingga klinisnya juga berbeda. Hal ini sesuai dengan penelitian Wahidiyat PA (2009) yang menyatakan splenektomi dapat dijadikan sebagai salah satu terapi untuk mengurangi kebutuhan transfusi darah pada kasus thalassemia $\beta / \mathrm{HbE} .{ }^{13}$

Splenektomi tetap harus dilakukan dengan pertimbangan yang matang mengingat risiko infeksi berat yang sering terjadi pasca-splenektomi. Umumnya splenomegali masif yang terjadi akibat transfusi yang tidak adekuat masih reversible. Untuk itu sebelum dilakukan splenektomi sebaiknya pasien diberikan transfusi yang adekuat untuk beberapa bulan dan kemudian dilakukan evaluasi ulang. Dengan demikian diharapkan ukuran limpa dapat mengecil sehingga operasi dapat ditunda ${ }^{6}$

Sebagai kesimpulan, terdapat perbedaan kebutuhan transfusi pasca-splenektomi berdasarkan jenis hipersplenisme dan genotip pasien. Kebutuhan transfusi berupa peningkatan hemoglobin, penurunan kebutuhan transfusi darah dan penurunan frekuensi transfusi darah pasca splenektomi akan lebih baik bila splenektomi dianjurkan pada keadaan hipersplenisme dini dan kasus thalassemia $\beta / \mathrm{HbE}$.

\section{Daftar pustaka}

1. Sofro ASM. Molecular pathology of the $\beta$-thalassemia in Indonesia. Southeast Asian J Trop Med Pub Health 1995;26:5-8.

2. Lanni F, Gani RA, Widuri, Rochdiyat W, Verawaty B, Sukmawati, dkk. $\beta$-thalassemia and hemoglobin-E traits in Yogyakarta population. Dipresentasikan pada $11^{\text {th }}$ International Conference on Thalassaemia and Haemoglobinophaties \& $13^{\text {rd }}$ International TIF Conference for Thalassaemia patients and parents. Singapore; 8-11 Oktober 2008.

3. Data Pusat Thalassaemia 2010.

4. Wahidiyat I, Wahidiyat PA. Genetic problems at present and their challenges in the future: Thalassemia as a model. Dipresentasikan pada Kongres Nasional Ilmu Kesehatan Anak XIII. Bandung; 4-7 Juli 2005.

5. Diunduh dari http://www.thalassemia.com/thal SOC_guide. pdf. Diakses tanggal 23 Oktober 2009.

6. Cappellini N, Cohen A, Eleftheriou A, Piga A, Porter J. Guidelines for the clinical management of thalassemia. Thalassemia International Federation; 2000.

7. Al-Salem AH, Nasserulla Z. Splenectomy for children with thalassemia. Int Surg 2002;87:269-73.

8. Hawsawi ZMA, Hummaida TI, Ismail GA. Splenectomy in thalassemia major: Experience at Madina Maternity and Children's Hospital. Ann Trop Paed 2001;21:155-8.

9. Wolff JA, Sitarz AL, Von Hofe FH. Effect of splenectomy on thalassemia. Pediatrics 1960;26:674-8.

10. Rebulla P, Modell B. Transfusion requirements and effects in patients with thalassemia major. Lancet 1991;337:277-80.

11. Anis N, Subhan A. Splenectomy in thalassemia: A personal experience. J Surg 2006;22:205-7. 
12. Smith CH, Erlandson ME, Stern G, Schulman I. The role of splenectomy in the management of thalassemia. Blood 1960;15:197-211.

13. Wahidiyat PA. Faktor-faktor pengubah manifestasi klinis thalassemia- $\beta / \mathrm{HbE}$ : Interaksi antara mutasi thalassemia-b, $-\alpha$, polimorfisme $X m n I-{ }^{\mathrm{G}} \gamma$, dan SNPs pada klaster gen globin- $\beta$ [disertasi]. Jakarta: Universitas Indonesia; 2009. 